\title{
Azithromycin versus erythromycin infusions prior to endoscopy in upper gastrointestinal bleeding
}

\author{
Danny Issa ${ }^{1}$, Sanjeev Solomon ${ }^{2}$, Jonathan Hillyard ${ }^{2}$, Brian Di Pace ${ }^{3}$, Christopher Young ${ }^{2}$, Patricia Uber ${ }^{4}$, \\ Adam Sima ${ }^{3}$, Reem Sharaiha ${ }^{5}$, George Smallfield ${ }^{2}$ \\ ${ }^{1}$ Division of Digestive Diseases, University of California-Los Angeles, Lost Angeles, CA, USA; ${ }^{2}$ Division of Gastroenterology, Hepatology and \\ Nutrition, Virginia Commonwealth University, Richmond, Virginia, USA; ${ }^{3}$ Department of Biostatistics, Virginia Commonwealth University, \\ Richmond, Virginia, USA; ${ }^{4}$ Pauley Heart Center and School of Pharmacy, Virginia Commonwealth University, Richmond, Virginia, USA; ${ }^{5}$ Weill \\ Cornell Medicine, New York Presbyterian Hospital, New York, NY, USA \\ Contributions: (I) Conception and design: S Solomon, G Smallfield, D Issa; (II) Administrative support: D Issa, S Solomon, G Smallfield; (III) \\ Provision of study materials or patients: D Issa, S Solomon, G Smallfield; (IV) Collection and assembly of data: D Issa, J Hillyard, C Young; (V) Data \\ analysis and interpretation: G Smallfield, B Di Pace, A Sima, D Issa; (VI) Manuscript writing: All authors; (VII) Final approval of manuscript: All \\ authors. \\ Correspondence to: Danny Issa, MD. Health Science Clinical Instructor of Medicine, David Geffen School of Medicine at UCLA, 200 Medical Plaza, \\ Suite 365, Los Angeles, CA 90095, USA. Email: dani87-md@hotmail.com.
}

Background: Intravenous erythromycin prior to endoscopy for upper gastrointestinal bleeding (GIB) improves outcomes but requires immediate preparation delaying administration in emergency cases. Azithromycin is readily available and does not require prolonged preparation. The aim of the study was to assess the effect of azithromycin in improving the quality of endoscopic visualization in upper GIB compared to erythromycin.

Methods: Patients admitted with upper GIB who received erythromycin or azithromycin before urgent endoscopy were included. Primary outcome of the quality of visualization was assessed by two gastroenterologists, blinded to the choice of infusion, using a scoring system ranging from 0 to 8 , with a maximum of 2 points assigned to the fundus, body, antrum and bulb.

Results: Sixty-six patients were included; 25 received azithromycin and 41 received erythromycin. Mean total visualization score was significantly higher with azithromycin compared to that with erythromycin $(6.8 \pm 1.4$ vs. $5.5 \pm 2.2$, respectively; $\mathrm{P}=0.01)$ and remained significant after adjusting for confounders (Diff: $0.01,1.88 ; \mathrm{P}=0.05)$. Secondary outcomes analyses showed a shorter LOS when given azithromycin compared to erythromycin [6 (3 to 9) vs. 8 (7 to 16) days, respectively, 95\% CI: $1.03,3.89 ; \mathrm{P}=0.04$ ]. Time between initiating the infusion and endoscopy was longer with azithromycin (Diff: $40.64 \mathrm{~min}$; 95\% CI: 7.23, 74.05; $\mathrm{P}=0.02$ ). Need for second look endoscopy, procedure time, blood transfusion requirements and procedurerelated complications did not differ between the groups.

Conclusions: Azithromycin infusion before endoscopy for upper GIB was associated with better visualization than that of erythromycin. Randomized trials are needed to validate these findings.

Keywords: Gastrointestinal bleeding (GIB); endoscopic visualization; azithromycin; endoscopic outcomes

Received: 16 January 2020; Accepted: 16 July 2020; Published: 25 October 2022.

doi: $10.21037 /$ tgh-20-51

View this article at: http://dx.doi.org/10.21037/tgh-20-51

\section{Introduction}

Upper gastrointestinal bleeding (GIB) is a common medical condition that is associated with substantial morbidity and mortality (1). It accounts for more than 250,000 hospitalizations annually in the United States, contributing to a significant burden and health costs (2). Despite the remarkable advances in diagnostic and therapeutic modalities, mortality rates of upper GIB continues to be 
significant, reaching $20 \%$ in high risk patients (3).

Urgent endoscopy plays an important role in the management of upper GIB and is considered the standard of care for active or recent GIB (4). While a bleeding source can be identified in most patients, $10-20 \%$ of cases remain without a clear source and require repeat procedures or surgical interventions to stop the bleeding (5). The diagnostic yield of an endoscopy and the success of interventions is largely dependent on the quality of visualization of the gastrointestinal tract.

Randomized controlled trials have shown that intravenous erythromycin infusion prior to endoscopy is more effective than placebo in improving visualization, and decrease the need for a second look while reducing costs (6-8). Erythromycin, administered in a dose of 1 to $3 \mathrm{mg} / \mathrm{kg}$, activates motilin receptors to increase gastric tone and phasic motor activity within minutes of infusion, leading to rapid gastric emptying $(9,10)$. However, erythromycin infusion requires "then and there" pharmacological preparation, which frequently delays its administration in urgent cases (11). Furthermore, a national shortage of intravenous erythromycin has been reported in the United States. Azithromycin is another macrolide with a modified ring structure from erythromycin which is also a motilin receptor agonist but offers the advantage of being more readily available and does not require immediate preparation (12). Motility studies suggest these two agents have broadly similar efficacy (13).

The primary aim of the study was to assess the effect of azithromycin infusion in improving the quality of endoscopic visualizations in patients with upper GIB and to compare it to that of erythromycin; the current standard of care. We present the following article in accordance with the STORBE reporting checklist (available at https://tgh. amegroups.com/article/view/10.21037/tgh-20-51/rc).

\section{Methods}

\section{Study design \& patient selection}

This is an observational, retrospective, case control study including patients admitted with upper GIB, along with patients hospitalized for other reasons and developed inhospital upper GIB between January 2014 and August 2017. All patients were included in the final analysis if they met the following criteria: at least 18 years of age and underwent urgent upper endoscopy which was defined as an esophagogastroduodenoscopy (EGD) within 12 hours of the initial bleed (4). Patients taking medications which can potentially affect gastric motility, including opioids and metoclopramide, patients with history of gastric surgeries, current use of antiarrhythmic drugs or antihistamine containing drugs and drugs with possible interactions with the study drugs were excluded. Patients with nasogastric or orogastric tubes were also excluded. The included patients were divided into two groups based on which pre-procedure motility agent was used: (I) patients receiving pre-procedure intravenous azithromycin infusion; (II) patients receiving pre-procedure intravenous erythromycin infusion. The decision whether to use a motility agent or not was up to the discretion of the operating endoscopist based on the time of the most recent bleeding episode and the estimation of GIB severity. The administration of the motility agent had to be started within 6 hours pre-procedure for the patient to be included in the study. Only patients who received azithromycin at a dosage of $250 \mathrm{mg}$ or erythromycin at a dosage of $250 \mathrm{mg}$ were included to ensure homogeneity of interventions. For patients who underwent a second look or multiple EGDs during the same hospitalization, only the first procedure was included in the study. The study was conducted in accordance with the Declaration of Helsinki (as revised in 2013). The study was approved by the Institutional Review Board of Virginia Commonwealth University (No. HM20008788) and informed consent was waived due to the retrospective nature.

\section{Outcome measurements}

The primary outcome of the study was the quality of endoscopic visualization. An objective scoring system was developed based on previously published data on the topic (8). The score ranged from 0 to 8 , with a maximum of 2 points assigned to each of the fundus, gastric body, antrum and duodenal bulb; a higher score indicates better visualization (Figure 1). Excellent visualization was defined as a score ozf $\geq 7$. To assess visualization, two gastroenterologists, blinded to the pre-procedure motility agent used, each reviewed the endoscopy images separately and provided a score. Patients with endoscopy pictures insufficient to calculate the score were excluded.

Secondary outcomes of the study included length of hospital stay (LOS), the number of packed red blood cells (pRBC) units transfused within 48 hours of the procedure, need for second-look endoscopy due to either failure to identify a bleeding site or re-bleeding, duration of the endoscopic procedure, and procedure-related complications. 

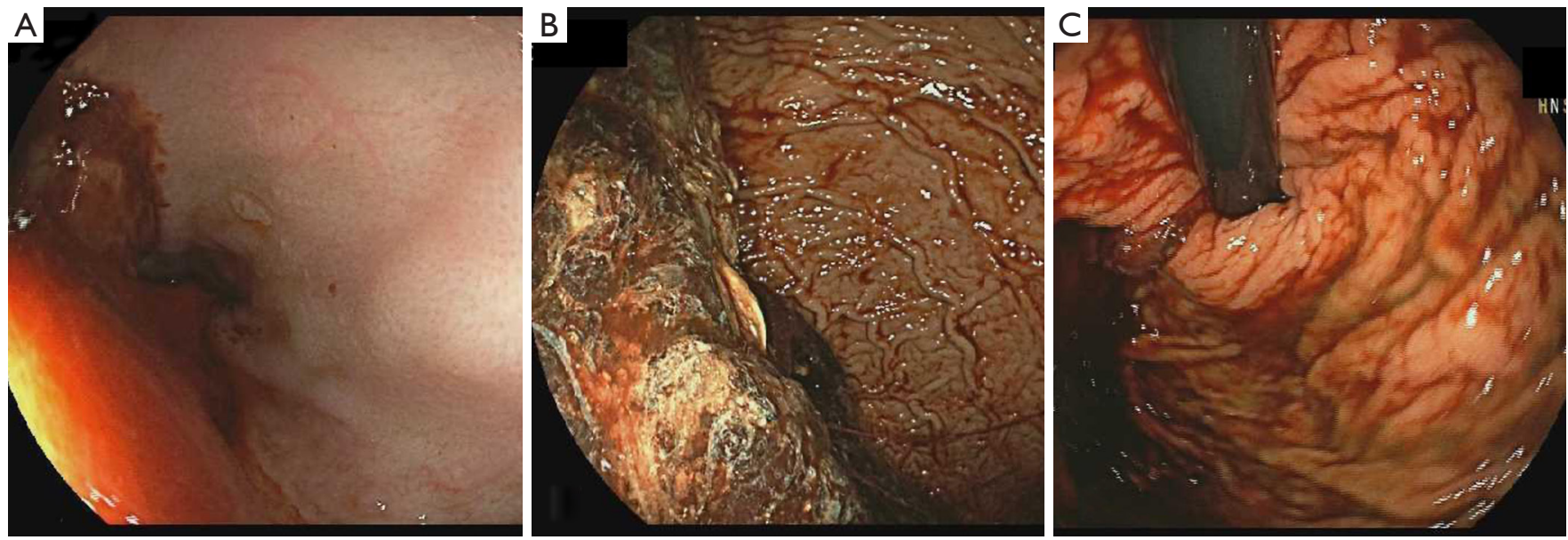

Figure 1 Endoscopic visualization in a patient with recent GIB who underwent upper endoscopy without the use of Azithromycin: (A) clots in the lower esophagus, (B) bezoar and clots in gastric body, (C) clots and fresh blood in gastric fundus.

Our original hypothesis was that erythromycin requires prolonged preparation, so an additional secondary outcome was the time between the administration of the infusion and the start of the procedure.

\section{Statistical analysis}

Continuous variables were summarized by means and standard deviations whereas categorical variables were summarized with frequencies and percentages. Analysis of Variance (ANOVA), Pearson's chi-squared tests, twosample $t$-tests, and Kaplan-Meier survival methods were used to compare the treatment groups. Fisher's exact tests or Wilcoxon rank-sum tests were used as needed. The concordance correlation coefficient was used to assess agreement between the two blinded reviewers and ranged between -1 (perfect disagreement) and 1 (perfect agreement), with zero indicating no agreement between the two measures.

Multiple linear regression models were fit to model the average total visualization score and time between infusion/ endoscopy. Cox proportional hazards model were fit for length of stay to account for patients that died during the hospitalization (censored). For each analysis, variables with $\mathrm{P}$ values $\leq 0.25$ from the bivariate associations with both the intervention used (Tables 1,2) and the total visualization score were included to account for confounders in the models. Unadjusted and adjusted mean treatment differences (95\% CI) and P values were provided. A sensitivity analysis for the survival analysis was performed where the analysis was limited to patients with a principal diagnosis of GIB. All statistical analyses were performed in SAS 9.4 (Cary, NC) using an alpha $=0.05$.

\section{Results}

The patients' demographic and basic characteristics were summarized in Table 1. Sixty-six patients who underwent urgent EGD for management of upper GIB at our facility were included in the study. Of these, $25(37.9 \%)$ patients received intravenous azithromycin and 41 (62.1\%) patients received intravenous erythromycin. The mean age was 58 (range, $24-86$ ) years and $76 \%$ were male. $34.4 \%$ of patients had at least 3 comorbidities and $50.6 \%$ had cirrhosis. Baseline clinical characteristics and the number of comorbidities were not significantly different between the groups. The concordance correlation coefficient for the total visualization scores between the two raters was 0.76 (95\% CI: 0.66, 0.83), meaning there was high agreement. The average total visualization score was used as the primary outcome.

\section{Primary outcomes}

The mean total visualization score was significantly higher in the azithromycin group compared to that of the erythromycin group $(6.8 \pm 1.4$ vs. $5.5 \pm 2.2$, respectively; $\mathrm{P}=0.01$ ).

Based on the bivariate associations with both the intervention used (Table 2) and the total visualization score, 
Table 1 Patient characteristics by treatment group

\begin{tabular}{|c|c|c|c|c|}
\hline Characteristics, n (\%) & Overall, $n=66$ & $\begin{array}{c}\text { Azithromycin, } \mathrm{n}=25 \\
(37.9 \%)\end{array}$ & $\begin{array}{l}\text { Erythromycin, } \mathrm{n}=41 \\
(62.1 \%)\end{array}$ & $P$ value \\
\hline $\mathrm{Age}^{\mathrm{a}}$ (years) & $57.1 \pm 13.8$ & $56.6 \pm 14.3$ & $57.6 \pm 11.5$ & 0.79 \\
\hline Gender, n (\%) & & & & 0.49 \\
\hline Female & $17(25.8)$ & $8(32.0)$ & $9(22.0)$ & \\
\hline Race, n (\%) & & & & 0.22 \\
\hline White & $33(50.0)$ & $10(40.0)$ & $23(56.1)$ & \\
\hline Other & $33(50.0)$ & $15(60.0)$ & $18(43.9)$ & \\
\hline Systolic BP & $110.8 \pm 23.1$ & $106.1 \pm 22.7$ & $110.3 \pm 22.7$ & 0.30 \\
\hline Hemoglobin ${ }^{a}$ & $8.3 \pm 2.2$ & $7.9 \pm 1.6$ & $8.4 \pm 2.3$ & 0.56 \\
\hline Hemoglobin nadir ${ }^{a}$ & $6.7 \pm 1.7$ & $6.3 \pm 1.6$ & $6.6 \pm 1.5$ & 0.29 \\
\hline Platelet count $^{\mathrm{a}}$ & $177.3 \pm 119.1$ & $192.1 \pm 151.6$ & $151.3 \pm 100.7$ & 0.17 \\
\hline $\mathrm{INR}^{\mathrm{a}}$ & $1.8 \pm 1.0$ & $2.3 \pm 1.7$ & $1.6 \pm 0.5$ & $0.02^{* \mathrm{~b}}$ \\
\hline Number of comorbidities, $\mathrm{n}(\%)$ & & & & 0.07 \\
\hline$\geq 3$ comorbidities & $23(34.8)$ & $13(52.0)$ & $10(24.4)$ & \\
\hline$<3$ comorbidities & $43(65.2)$ & $12(48.0)$ & $31(75.6)$ & \\
\hline
\end{tabular}

${ }^{a}$, continuous variables presented as mean $\pm \mathrm{SD} ;{ }^{b}$, Kruskal-Wallis test; ${ }^{*}$, statistical significance indicated (alpha 0.05$)$.

the number of pRBC units transfused and comorbidities $(\geq 3$ $v s .<3)$ were identified as confounding variables $(\mathrm{P}<0.25)$. After adjusting for the confounders, the mean total visualization score remained higher in the azithromycin group compared to the erythromycin group (Diff: 0.01, $1.88 ; \mathrm{P}=0.05)$. Seventeen patients $(68 \%)$ who received preprocedure azithromycin achieved excellent visualization compared to 16 patients (41\%) received erythromycin $(\mathrm{P}=0.09)$ (Table 3, Figure 2). The adjusted mean total visualization scores $(95 \% \mathrm{CI})$ for the intervention groups are displayed in Figure 3.

\section{Secondary outcomes}

A Cox proportional hazards model was fit to model the length of stay. There were 12 patients excluded from this analysis due to a missing length of stay and 12 (14.81\%) patients censored. No differences in the average LOS between azithromycin and erythromycin were observed $(\mathrm{P}=0.88)$. A sensitivity analysis was performed on a subset of patients with a principal diagnosis of GIB (excluding 16 patients), of which 11 (16.92\%) patients were censored. The sensitivity analysis showed that patients admitted with a principal diagnosis of GIB had a shorter LOS when given azithromycin compared to erythromycin [6 (3 to 9) vs. 8 (7 to 16) days, respectively, HR 2.00; 95\% CI: 1.03 , 3.89; $\mathrm{P}=0.04]$. After adjusting for the number of $\mathrm{pRBC}$ units transfused and comorbidities, this effect remained significant (HR 1.97; 95\% CI: 1.00, 3.88; P=0.05).

The number of pRBC units transfused within 48 hours of 
Table 2 Outcomes by treatment group

\begin{tabular}{|c|c|c|c|c|}
\hline Characteristics & Overall, $\mathrm{n}=66$ & $\begin{array}{c}\text { Azithromycin, } \mathrm{n}=25 \\
(37.9 \%)\end{array}$ & $\begin{array}{c}\text { Erythromycin, } \mathrm{n}=41 \\
(62.1 \%)\end{array}$ & $P$ value \\
\hline Total visualization score ${ }^{a}$ & $6.0 \pm 1.9$ & $6.8 \pm 1.4$ & $5.5 \pm 2.2$ & $0.01^{*}$ \\
\hline Excellent visualization, $\mathrm{n}(\%)$ & & & & 0.09 \\
\hline Yes & $33(51.6)$ & $17(68.0)$ & $16(41.0)$ & \\
\hline Length of stay (days): GI bleeding ${ }^{d}$ & $7.0(7.0,10.0)$ & $6.0(3.0,9.0)$ & $8.0(7.0,16.0)$ & $0.08^{\mathrm{e}}$ \\
\hline Length of stay (days): all diagnoses ${ }^{d}$ & $9.0(7.0,10.0)$ & $9.0(6.0,11.0)$ & $10.0(7.0,16.0)$ & $0.75^{e}$ \\
\hline Time between infusion/endoscopy ${ }^{a}(\mathrm{~min})$ & $76.0 \pm 67.7$ & $100.7 \pm 75.6$ & $60.1 \pm 57.8$ & $0.02^{* \mathrm{~b}}$ \\
\hline Number of $p R B C$ units transfused ${ }^{a}$ & $2.8 \pm 3.0$ & $2.8 \pm 1.7$ & $3.4 \pm 4.0$ & $0.17^{c}$ \\
\hline Yes & $14(21.2)$ & $3(12.0)$ & $11(26.8)$ & \\
\hline No & $52(78.8)$ & $22(88.0)$ & $30(73.2)$ & \\
\hline
\end{tabular}

${ }^{a}$, continuous variables presented as mean $\pm \mathrm{SD}$; ${ }^{\mathrm{b}}$, two sample t-test; ${ }^{\mathrm{c}}$, Kruskal-Wallis test; ${ }^{\mathrm{d}}$, presented as median (95\% $\left.\mathrm{Cl}\right) ;{ }^{\mathrm{e}}$, log-rank test; * , statistical significance indicated (alpha 0.05).

Table 3 Unadjusted and adjusted association of total visualization score and intervention used

\begin{tabular}{|c|c|c|c|c|}
\hline Total visualization score ${ }^{a}$ & Unadjusted estimate $(95 \% \mathrm{Cl})$ & $P$ value & Adjusted $^{\ddagger}$ estimate $(95 \% \mathrm{Cl})$ & $P$ value \\
\hline Comorbidities ( $\geq 3$ vs. $<3$ ) & - & - & $1.24(0.43,2.06)$ & $<0.01^{*}$ \\
\hline 1-unit increase in pRBC transfused & - & - & $-0.14(-0.26,-0.01)$ & 0.04 \\
\hline
\end{tabular}

endoscopy was not significantly different between patients given erythromycin and patients given azithromycin (mean: $3.4 \pm 4.0$ vs. $2.8 \pm 1.7$, respectively; $\mathrm{P}=0.17)$.

Using multiple linear regression model, the time between infusion and endoscopy was compared between the azithromycin and erythromycin groups. Mean time between initiating the infusion and endoscopy was higher in the azithromycin group compared to that of the erythromycin group (Diff: $40.64 \mathrm{~min}$; 95\% CI: 7.23, 74.05; $\mathrm{P}=0.02$ ). After adjusting for the number of $\mathrm{pRBC}$ units transfused and comorbidities, the average time between infusion and endoscopy remained higher in the azithromycin group compared to the erythromycin group (Diff: $40.42 \mathrm{~min}$; $95 \%$ CI: 5.10, 75.74; $\mathrm{P}=0.03)$. Four patients were ordered erythromycin; however, the infusion was not delivered on time before starting the procedure, compared to zero patients in the azithromycin group. These four patients were not included in the analysis.

There was no statistical difference in mean procedure time between the treatment groups (mean 19.2 $\pm 6.8 \mathrm{~min}$ for azithromycin $v s$. mean $18.5 \pm 12.3$ min for erythromycin; $\mathrm{P}=0.95)$.

There were nominally fewer patients who required a second look endoscopy in the azithromycin group compared to the erythromycin group [3 (12.0\%) vs. 11 (26.8\%), respectively; $\mathrm{P}=0.33$. There were only 4 patients required a second look endoscopy due to poor visibility. No procedure-related complications were encountered. 

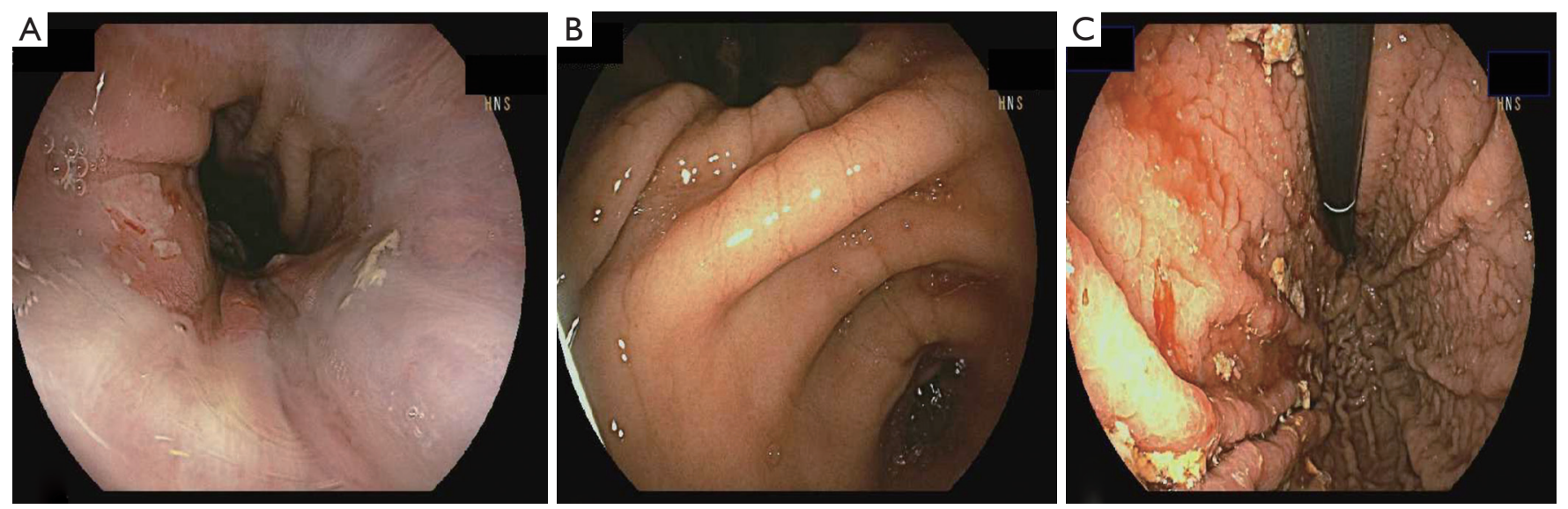

Figure 2 Endoscopic visualization in a patient with recent GIB who underwent upper endoscopy following the use of Azithromycin: (A) good visualization in esophagus, (B) excellent visualization in gastric body, (C) excellent visualization in gastric fundus.

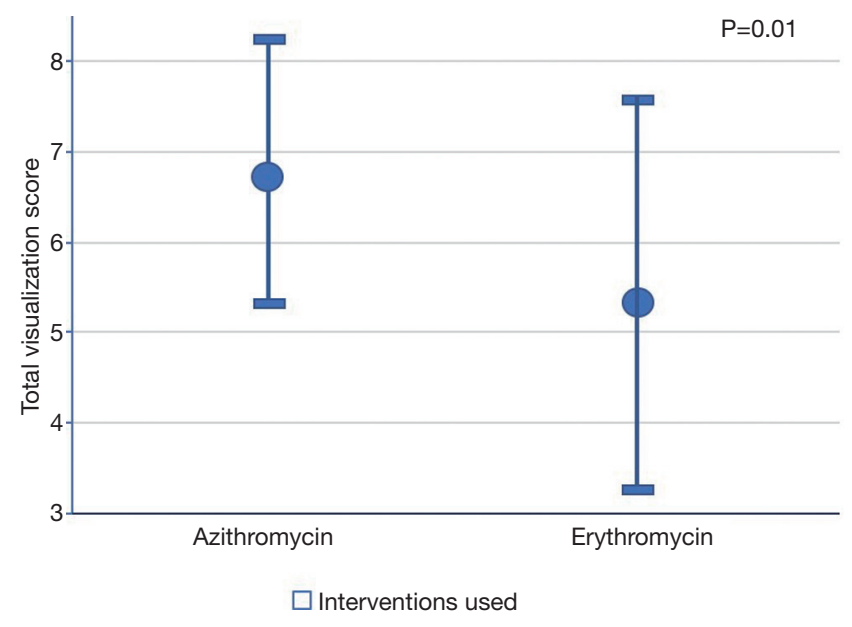

Figure 3 Mean total visualization score in the azithromycin and erythromycin groups.

Table 4 summarizes the unadjusted and adjusted secondary outcomes.

\section{Discussion}

The primary objective of the study was to assess the effect of azithromycin and erythromycin on gastric cleansing and thereby the quality of endoscopic visualization in patients with acute upper gastrointestinal bleeding. The endoscopic total visualization score, an objective score graded by two blinded gastroenterologists, was higher in the azithromycin group. Thus, our study shows azithromycin to be associated with better visualization scores compared to erythromycin which is the current standard of care. When considering only patients hospitalized for GIB as the principal diagnosis, the length of hospital stay was shorter in the azithromycin group compared to the erythromycin group. Other outcomes of blood transfusion requirements and procedure duration were not different between the two groups.

Erythromycin works as a motilin receptor agonist that accelerates gastric emptying by inducing antral contractions. It has a powerful effect on gastric clearing with the optimal results achieved when erythromycin is administered intravenously as 2 to $3 \mathrm{mg} / \mathrm{kg}$ and given over 10 to 30 minutes. Multiple randomized trials and meta-analyses suggested benefit of the use of erythromycin in upper GIB $(7,14)$. The American College of Gastroenterology guidelines on the management of ulcer bleeding, published in 2012, include intravenous erythromycin as a recommendation for pre-endoscopy medical therapy (15).

One disadvantage of the use of erythromycin is the need for relatively prolonged preparation as the intravenous dilution requires adding a buffering solution (11). The drug must be used within 8 hours of preparing, i.e., it is not meant to be stored or premixed, and therefore it is unlikely that it will be made ahead of time. When it comes to emergent cases, a delay of 50-60 minutes can be significant and may result in postponing the procedure and slowing the control of bleeding. In our experience, it requires the pharmacy approximately 55 minutes to prepare the intravenous erythromycin solution. Additionally, a national shortage of intravenous erythromycin in the U.S. presents a strong need for an effective alternative. Azithromycin does not require prolonged preparation and can be premixed and 
Table 4 Unadjusted and adjusted associations of secondary outcomes

\begin{tabular}{|c|c|c|c|c|c|}
\hline Characteristics & Comparison & $\begin{array}{l}\text { Unadjusted estimate } \\
\qquad(95 \% \mathrm{Cl})\end{array}$ & $P$ value & $\begin{array}{c}\text { Adjusted }{ }^{\ddagger} \text { estimate } \\
(95 \% \mathrm{Cl})\end{array}$ & $P$ value \\
\hline Time between infusion/endoscopy ${ }^{\mathrm{a}}$ (min) & Azith-Eryth & $40.64(7.23,74.05)$ & $0.02^{*}$ & $40.42(5.10,75.74)$ & $0.03^{*}$ \\
\hline Length of stay ${ }^{b}$ (days): all diagnoses & Azith-Eryth & $0.95(0.52,1.74)$ & 0.88 & $0.80(0.43,1.47)$ & 0.47 \\
\hline Length of stay ${ }^{\mathrm{b}}$ (days): GI bleeding & Azith-Eryth & $2.00(1.03,3.89)$ & $0.04^{*}$ & $1.97(1.00,3.88)$ & $0.05^{\star}$ \\
\hline
\end{tabular}

${ }^{a}$, reported as mean difference $(95 \% \mathrm{Cl}) ;{ }^{b}$, reported as HR $(95 \%$ Wald $\mathrm{Cl}) ;{ }^{\ddagger}$, adjusted for number of pRBC units transfused and comorbidities ( $\geq 3$ vs. $<3$ ); ${ }^{*}$, statistical significance indicated (alpha 0.05 ).

stored in solution in cold temperatures for 7 days (12). It is readily available in almost all emergency and intensive care units as a prerequisite of sepsis and community acquired pneumonia protocols. Within 5 minutes, intravenous azithromycin solution can be bedside for emergent cases. In fact, four patients included in our study with upper GIB were ordered erythromycin pre-endoscopy, however, this could not be made in time compared to zero missed infusions in the azithromycin group. Furthermore, the time from infusion to endoscopy was longer in the azithromycin group. On average, patients given intravenous azithromycin had 41 additional minutes of infusion prior to the start of the endoscopy compared to those given erythromycin, suggesting the drug preparation and administration were faster.

Azithromycin use is considered relatively safe. However, caution should be practiced in patients with cardiovascular disease as azithromycin, like other macrolide antibiotics, can prolong the QT interval, potentially causing lethal ventricular arrhythmias (16). Carbonell et al. suggested a lower infusion rate of 20 minutes for intravenous erythromycin to prevent cardiac arrhythmias, compared to 5 minutes described in previous studies (17). As with most antibiotics, the use of azithromycin can increase the risk of Clostridium difficile and associated colitis (18).

There are several limitations of this study that merit discussion. This is a retrospective observational analysis and is susceptible to inherent limitations of this type of study design. These include selection bias previously discussed, limitations on endoscopic images available and reliance on data recorded in the medical record. This cohort is from single tertiary referral center, so the results may not be generalizable to all patient populations. Furthermore, the national shortage in IV erythromycin is reported in the US, therefore generalizing to an international practice should be used with caution. Lastly, while we tried to adjust for all possible statistically significant confounding factors, the presence of other unknown or unmeasured variables cannot be ignored. This is especially important when evaluating length of stay as it is typically influenced by several medical and non-medical factors, thus caution needs to be used before drawing definite conclusions.

To the best of our knowledge, this is the first study to examine the clinical effect of azithromycin on gastric visualization. It is also the first study to compare azithromycin to erythromycin for gastric visualization during urgent EGD. The time interval between administering azithromycin and starting the procedure was longer compared to the erythromycin group. This longer time interval allows longer duration of drug activity perhaps leading to more complete clearance of gastric contents leading to better visualization in the azithromycin group; a finding that proves our original hypothesis. Moreover, the visualization score used to evaluate the effect of the study drugs was objectively graded by gastroenterologists blinded to the motility drug used and inter-observer variability was low.

In conclusion, this study shows the use of intravenous azithromycin before urgent endoscopy was associated with better endoscopic visualization than intravenous erythromycin. Azithromycin can be made ready and delivered on time in emergent cases, which may be the source of its advantage. We therefore suggest further prospective trials to validate these findings and propose using intravenous azithromycin in acute GIB to prevent unnecessary delays and improve the yield of endoscopic interventions.

\section{Acknowledgments}

We sincerely thank Dr. Paul Moayyedi for comments that greatly improved the manuscript.

Funding: None. 


\section{Footnote}

Reporting Checklist: The authors have completed the STORBE reporting checklist. Available at https://tgh. amegroups.com/article/view/10.21037/tgh-20-51/rc

Data Sharing Statement: Available at https://tgh.amegroups. com/article/view/10.21037/tgh-20-51/dss

Peer Review File: Available at https://tgh.amegroups.com/ article/view/10.21037/tgh-20-51/prf

Conflicts of Interest: All authors have completed the ICMJE uniform disclosure form (available at https://tgh.amegroups. com/article/view/10.21037/tgh-20-51/coif). RS reports that he is a consultant for Olympus Co. USA, Boston Scientific Co., Cook medical Co., outside the submitted work. The other authors have no conflicts of interest to declare.

Ethical Statement: The authors are accountable for all aspects of the work in ensuring that questions related to the accuracy or integrity of any part of the work are appropriately investigated and resolved. The study was conducted in accordance with the Declaration of Helsinki (as revised in 2013). The study was approved by the Institutional Review Board of Virginia Commonwealth University (No. HM20008788) and informed consent was waived due to the retrospective nature.

Open Access Statement: This is an Open Access article distributed in accordance with the Creative Commons Attribution-NonCommercial-NoDerivs 4.0 International License (CC BY-NC-ND 4.0), which permits the noncommercial replication and distribution of the article with the strict proviso that no changes or edits are made and the original work is properly cited (including links to both the formal publication through the relevant DOI and the license). See: https://creativecommons.org/licenses/by-nc-nd/4.0/.

\section{References}

1. Lanas A, Perez-Aisa MA, Feu F, et al. A nationwide study of mortality associated with hospital admission due to severe gastrointestinal events and those associated with nonsteroidal antiinflammatory drug use. Am J Gastroenterol 2005;100:1685-93.

2. Abougergi MS, Travis AC, Saltzman JR. The in-hospital mortality rate for upper GI hemorrhage has decreased over 2 decades in the United States: a nationwide analysis. Gastrointest Endosc 2015;81:882-8.e1.

3. Hearnshaw SA, Logan RF, Lowe D, et al. Acute upper gastrointestinal bleeding in the UK: patient characteristics, diagnoses and outcomes in the 2007 UK audit. Gut 2011;60:1327-35.

4. Hwang JH, Fisher DA, Ben-Menachem T, et al. The role of endoscopy in the management of acute non-variceal upper GI bleeding. Gastrointest Endosc 2012;75:1132-8.

5. Enestvedt BK, Gralnek IM, Mattek N, et al. An evaluation of endoscopic indications and findings related to nonvariceal upper-GI hemorrhage in a large multicenter consortium. Gastrointest Endosc 2008;67:422-9.

6. Pateron D, Vicaut E, Debuc E, et al. Erythromycin infusion or gastric lavage for upper gastrointestinal bleeding: a multicenter randomized controlled trial. Ann Emerg Med 2011;57:582-9.

7. Coffin B, Pocard M, Panis Y, et al. Erythromycin improves the quality of EGD in patients with acute upper GI bleeding: a randomized controlled study. Gastrointest Endosc 2002;56:174-9.

8. Frossard JL, Spahr L, Queneau PE, et al. Erythromycin intravenous bolus infusion in acute upper gastrointestinal bleeding: a randomized, controlled, double-blind trial. Gastroenterology 2002;123:17-23.

9. Peeters TL. Erythromycin and other macrolides as prokinetic agents. Gastroenterology 1993;105:1886-99.

10. Bruley des Varannes S, Parys V, Ropert A, et al. Erythromycin enhances fasting and postprandial proximal gastric tone in humans. Gastroenterology 1995;109:32-9.

11. Hospira I, Lake Forest, IL. Erythrocin ${ }^{\circledR}$ Lactobionate (erythromycin lactobionate). 2006. Packager: Hospira, Inc.

12. Azithromycin Product Information (azithromycin). Pfizer US Pharmaceuticals, New York, NY, 1981.

13. Broad J, Sanger GJ. The antibiotic azithromycin is a motilin receptor agonist in human stomach: comparison with erythromycin. Br J Pharmacol 2013;168:1859-67.

14. Altraif I, Handoo FA, Aljumah A, et al. Effect of erythromycin before endoscopy in patients presenting with variceal bleeding: a prospective, randomized, double-blind, placebo-controlled trial. Gastrointest Endosc 2011;73:245-50.

15. Laine L, Jensen DM. Management of patients with ulcer bleeding. Am J Gastroenterol 2012;107:345-60; quiz 61.

16. Ray WA, Murray KT, Hall K, et al. Azithromycin and the risk of cardiovascular death. $\mathrm{N}$ Engl J Med 2012;366:1881-90.

17. Carbonell N, Pauwels A, Serfaty L, et al. Erythromycin 


\section{Page 9 of 9}

infusion prior to endoscopy for acute upper gastrointestinal bleeding: a randomized, controlled, double-blind trial. Am J Gastroenterol 2006;101:1211-5.

doi: $10.21037 / \operatorname{tgh}-20-51$

Cite this article as: Issa D, Solomon S, Hillyard J, Di Pace B, Young C, Uber P, Sima A, Sharaiha R, Smallfield G. Azithromycin versus erythromycin infusions prior to endoscopy in upper gastrointestinal bleeding. Transl Gastroenterol Hepatol 2022;7:35.
18. Gorenek L, Dizer U, Besirbellioglu B, et al. The diagnosis and treatment of Clostridium difficile in antibioticassociated diarrhea. Hepatogastroenterology 1999;46:343-8. 